Article

\title{
In Situ Plasma Monitoring of PECVD nc-Si:H Films and the Influence of Dilution Ratio on Structural Evolution
}

\author{
Yu-Lin Hsieh ${ }^{1}$, Li-Han Kau ${ }^{2}$, Hung-Jui Huang ${ }^{2}$, Chien-Chieh Lee ${ }^{3}$, Yiin-Kuen Fuh ${ }^{1, *}$ (iD \\ and Tomi T. Li $^{1}$ \\ 1 Department of Mechanical Engineering, National Central University, Taoyuan 32001, Taiwan; \\ firenze114@gmail.com (Y.-L.H.); tomili@cc.ncu.edu.tw (T.T.L.) \\ 2 Opto-mechatronics Engineering, National Central University, Taoyuan 32001 Taiwan; \\ as811224@gmail.com (L.-H.K.); rayan811029@gmail.com (H.-J.H.) \\ 3 Optical Science Center, National Central University, Taoyuan 32001 Taiwan; jjlee@ncu.edu.tw \\ * Correspondence: mikefuh@cc.ncu.edu.tw; Tel.: +886-34227151 (ext. 34305)
}

Received: 12 April 2018; Accepted: 2 July 2018; Published: 6 July 2018

\begin{abstract}
We report plasma-enhanced chemical vapor deposition (PECVD) hydrogenated nano-crystalline silicon (nc-Si:H) thin films. In particular, the effect of hydrogen dilution ratio $\left(\mathrm{R}=\mathrm{H}_{2} / \mathrm{SiH}_{4}\right)$ on structural and optical evolutions of the deposited nc-Si:H films were systematically investigated including Raman spectroscopy, Fourier-transform infrared spectroscopy (FTIR) and low angle X-ray diffraction spectroscopy (XRD). Measurement results revealed that the nc-Si:H structural evolution, primarily the transition of nano-crystallization from the amorphous state to the nanocrystalline state, can be carefully induced by the adjustment of hydrogen dilution ratio $(R)$. In addition, an in situ plasma diagnostic tool of optical emission spectroscopy (OES) was used to further characterize the crystallization rate index $\left(\mathrm{H}_{\alpha}{ }^{*} / \mathrm{SiH}^{*}\right)$ that increases when hydrogen dilution ratio $(R)$ rises, whereas the deposition rate decreases. Another in situ plasma diagnostic tool of quadruple mass spectrometry (QMS) also confirmed that the "optimal" range of hydrogen dilution ratio $(R=30-40)$ can yield nano-crystalline silicon (n-Si:H) growth due to the depletion of higher silane radicals. A good correlation between the plasma characteristics by in situ OES/QMS and the film characteristics by XRD, Raman and FTIR, for the transition of a-Si:H to nc-Si:H film from the hydrogen dilution ratio, was obtained.
\end{abstract}

Keywords: PECVD; plasma diagnostics; nc-Si:H; RF-PECVD; Fourier-transform infrared spectroscopy (FTIR); quadruple mass spectrometry (QMS); optical emission spectroscopy (OES); X-ray diffraction spectroscopy (XRD)

\section{Introduction}

Hydrogenated nanocrystalline silicon (nc-Si:H) is a promising material to have distinguishing characteristics of higher carrier mobility, greater doping efficiency and efficient visible photoluminescence [1-3]. Generally, the re-crystallization technique such as rapid thermal annealing [4], excimer laser [5], and aluminium induced crystallization [6] were typically used to obtain the nc-Si:H films with a variety of applications in silicon-based tandem device solar cells $[7,8]$, photovoltaic and optoelectronic devices [9].

On the other hand, several chemical vapor deposition (CVD) techniques have been widely used to deposit the thin films include hot wire CVD (HW-CVD) [10], layer-by-layer (LBL) deposition [11], magnetron sputtering [12], electron cyclotron resonance CVD [13], and plasma enhanced CVD (PECVD) [11] and its variant, very high frequency plasma-enhanced chemical vapor deposition 
(VHF-PECVD) [14]. In particular, PECVD is the one of the standard industrial processes in the solar cells and Thin-Film Transistor (TFT) technology.

In the PECVD growth of thin films, critical process conditions, including the gas flow composition, chamber environment, RF power density $[15,16]$, process gas mixtures of hydrogen $\left(\mathrm{H}_{2}\right)$ and silane $\left(\mathrm{SiH}_{4}\right)[17,18]$, should be carefully monitored. Therefore, plasma diagnostics is essentially useful for investigations of thin film growth plasma conditions. Several diagnostic tools such as optical emission spectroscopy (OES) [19,20] and quadrupole mass spectrometry (QMS) [21-23] were previously reported to in situ monitor the plasma chemistry. The deposited thin films can be further characterized by Fourier-transform infra-red spectroscopy (FTIR) [24,25], X-ray diffraction spectroscopy (XRD) and Raman spectroscopy such that the structure of the materials can be extensively investigated. For the low temperature deposition of polycrystalline silicon and solar cell applications, a thorough review had been reported and the characteristics of deposition and physical properties were comprehensively indicated to be the guiding parameters for achieving poly Si films at high deposition rates [26].

In this paper, we present the effect of hydrogen dilution ratio $\left(R=\mathrm{H}_{2} / \mathrm{SiH}_{4}\right)$ on structural and optical properties of PECVD nc-Si:H films. In addition, Raman spectroscopy and XRD tools are performed to study the growth of a-Si:H transition to nanocrystalline silicon (nc-Si:H). By varying the hydrogen dilution ratio, the film properties were experimentally correlated with the emission intensities of the excited radicals from plasma diagnostic tools of OES and QMS. The obtained results demonstrated that hydrogen dilution ratio $(R)$ played a critical role in PECVD nc-Si:H films.

\section{Experimental}

Intrinsic hydrogenated nanocrystalline silicon (nc-Si:H) films were PECVD deposited with silane and hydrogen which were used as a source gas and diluent, respectively. The main purpose of this study aims to quantatively characterize the amorphous to nano-crystalline transition, therefore, a systematic variation of hydrogen dilution ratio $\left(R=\mathrm{H}_{2} / \mathrm{SiH}_{4}\right)$ of $5-40$ was carried out with $\mathrm{RF}$ power frequency $13.56 \mathrm{MHz}$ and substrate temperature $\left(210^{\circ} \mathrm{C}\right)$. For characterization purpose, films were deposited on $2 \times 2 \mathrm{~cm}^{2} \mathrm{Cz}(100)$ n-type 1-5 $\Omega \mathrm{cm}^{2}$ single-side polished wafer and Corning eagle XG glass (Corning Incorporated, Corning, NY, USA). Prior to deposition, the wafers were cleaned using $\mathrm{H}_{2} \mathrm{O}_{2}: \mathrm{H}_{2} \mathrm{SO}_{4}=1: 2$ solution for $5 \mathrm{~min}$, followed by dipping in $2 \% \mathrm{HF}$ for $1 \mathrm{~min}$ to remove native oxide, rinsed in DI water, dried in $\mathrm{N}_{2}$ atmosphere and then the wafers were immediately transferred into vacuum chamber to prevent wafers from the native oxide layer growth.

Raman spectroscopy (Horiba iHR550, Irvine, CA, USA), Fourier-transform infrared spectroscopy (FTIR-Perkin Elmer Spectrum 100, Shelton, CT, USA), Quadruple mass spectrometry (QMS-Hiden PSM003P, Warrington, United Kingdom), Optical emission spectroscopy (OES-ocean optics usb2000+, Winter Park, FL, USA), X-ray diffraction spectroscopy (XRD-PANalytical Empyrean, Royston, United Kingdom) measurements were performed. The film thicknesses were measured using a profilometer of Alpha-step (KLA-Tencor D-300, Milpitas, CA, USA). OES measurement was primarily used to investigate the in situ excited radicals inside plasma. QMS is adopted to quantitatively monitor the plasma condition in assisting the development of deposition process.

Films were deposited in a commercially available PECVD unit (Creating Nano-Technologies, PE-001, Tainan, Taiwan) as schematically shown in Figure 1. This parallel plate PECVD reactor with two attached plasma in situ diagnostics of OES and QMS on the side is used. The in situ QMS was applied and the position of the QMS orifice is fixed to the chamber wall quartz window. Threshold ionization mass spectrometry (TIMS) was also used to detect atomic mass unit (amu) in the range of $0-90$ and the time resolution is set at $\sim 240 \mathrm{~s}$ sweeping time during measurements. The process chamber was kept at a base pressure less than $10^{-6}$ Torr via the coupled turbo molecular pump (TMP). The detailed deposition parameters are illustrated in Table 1. 


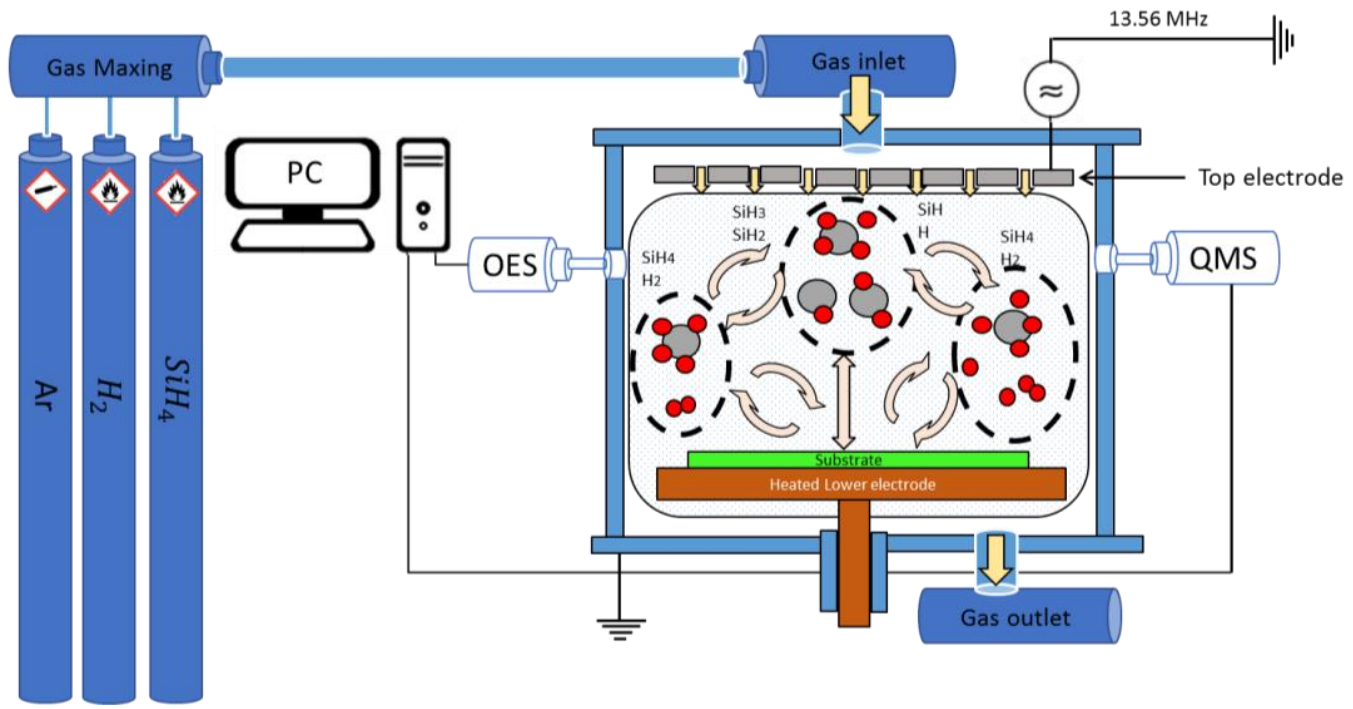

Figure 1. Schematic diagram of the PECVD equipment with a $13.56 \mathrm{MHz}$ radio frequency (RF) and in situ plasma diagnostic tool of OES and QMS on the side. $\mathrm{H}_{2}$ gas, $\mathrm{SiH}_{4}$ gas and Ar gas are introduced in the chamber from upstream of the plasma zone.

Table 1. Main process parameters used of the deposition of intrinsic nc-Si:H thin films by PECVD.

\begin{tabular}{|c|c|c|c|c|c|c|c|c|}
\hline \multirow{2}{*}{$\begin{array}{l}\text { Source } \\
\text { Gases }\end{array}$} & \multirow{2}{*}{ Pressure } & \multirow{2}{*}{ Power } & \multicolumn{3}{|c|}{ Gas Flow Ratio } & \multirow{2}{*}{$\begin{array}{l}\text { Deposition } \\
\text { Time }\end{array}$} & \multirow{2}{*}{ Distance } & \multirow{2}{*}{$\begin{array}{c}\text { Substrate } \\
\text { Temperature }\end{array}$} \\
\hline & & & (1) $\mathrm{Ar}$ & (2) $\mathrm{SiH}_{4}$ & (3) $\mathrm{H}_{2}$ & & & \\
\hline $\mathrm{Ar}, \mathrm{SiH}_{4}, \mathrm{H}_{2}$ & $\begin{array}{l}300 \\
\text { mTorr }\end{array}$ & $100 \mathrm{~W}$ & $3 \mathrm{sccm}$ & $5 \mathrm{sccm}$ & $\begin{array}{c}25,50,100 \\
150,200 \mathrm{sccm}\end{array}$ & $60 \mathrm{~min}$ & $25 \mathrm{~mm}$ & $210^{\circ} \mathrm{C}$ \\
\hline
\end{tabular}

\section{Results and Discussion}

\subsection{Effect of the Hydrogen Dilution Ratio on the Deposition Rate}

Figure 2 shows the relationship between the deposition rate (black circle line), $\mathrm{SiH}^{*} / \mathrm{Ar}$ and $\mathrm{H}_{\alpha}{ }^{*}$ / Ar ratio as extrapolated from optical emission spectra as a function of different hydrogen dilution ratio $\left(R=\mathrm{H}_{2} / \mathrm{SiH}_{4}\right)$. In Figure 2, the intensity of the $\mathrm{H}_{\alpha}{ }^{*} / \mathrm{Ar}$ ratio is comparatively higher than that of the $\mathrm{SiH}^{*} / \mathrm{Ar}$ counterpart for the hydrogen dilution ratio $(R)$, which is greater than 20 . It was experimentally observed that the deposition rate decreases with the increase in hydrogen dilution ratio $(R)$. Similar trends between the $\mathrm{SiH}^{*}$ intensity and the deposition rate were reported [27], and, furthermore, ion bombardment [28] and hydrogen etch $\left(\mathrm{H}_{\alpha} * / \mathrm{Ar}\right.$ ratio) [29] impact will result in heavy defects and easily crumbled film. Thus, the deposition rate decreases as hydrogen dilution ratio increases, as shown in Figure 2. 


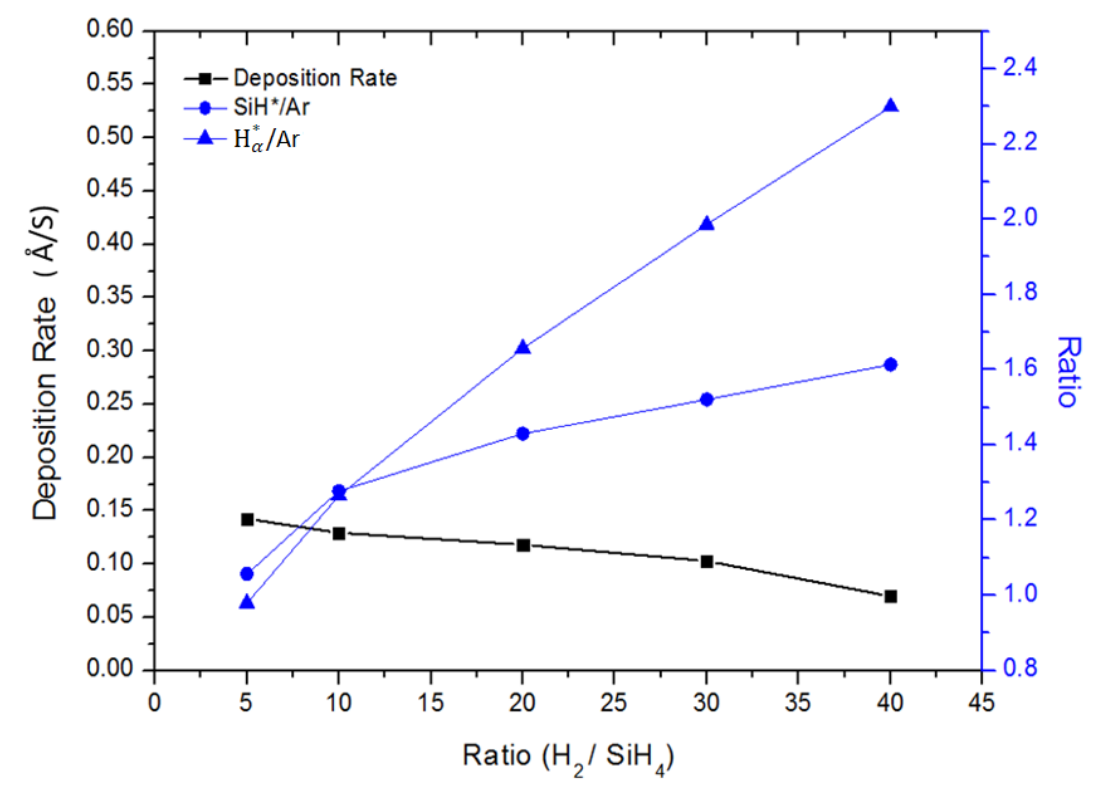

Figure 2. Effect of the hydrogen dilution ratio $(R)$ on the deposition rate (black line) the $\mathrm{SiH}^{*}$ emission intensity (blue circle line) and $\mathrm{H}_{\alpha}{ }^{*}$ emission intensity (blue triangle line).

\subsection{Low Angle XRD Analysis}

XRD patterns of five typical samples under the same RF power $(100 \mathrm{~W})$ but different hydrogen dilution ratios are presented in Figure 3. The transformation from the amorphous to the partially crystalline state can be observed for peaks at angles $28.5^{\circ}, 47.2^{\circ}$ and $56.2^{\circ}$, as assigned to $\mathrm{Si}(111), \operatorname{Si}(221)$ and $\mathrm{Si}(311)$ reflection planes of faced-centered cubic silicon, respectively.

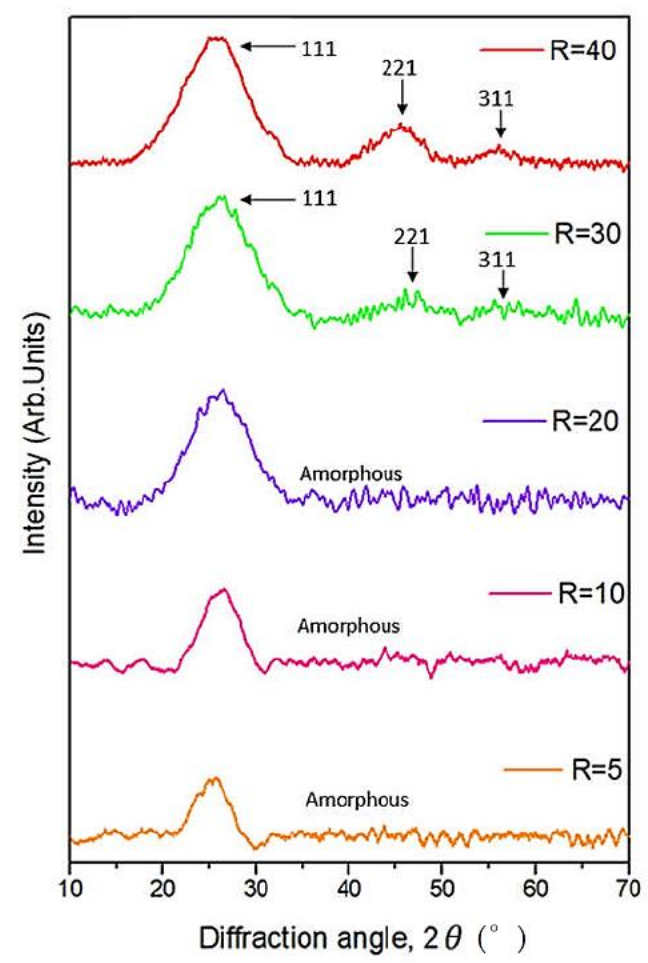

Figure 3. Low angle XRD pattern of nc-Si:H films deposited under different hydrogen dilution ratio (R) using the PECVD method. 
In the case of low hydrogen dilution ratio $(R=5)$, no crystal grains and apparent structural evolution were detected in the a-Si:H thin films. Further increasing the hydrogen dilution ratio ( $R=10$ and 20) still shows amorphous films centered at $2 \theta \sim 27.5^{\circ}$. On the other hand, films deposited with higher hydrogen dilution ratio $(R=30$ and 40$)$ the XRD pattern show three peaks at $2 \theta \sim 27.3^{\circ}$, $46.8^{\circ}$ and $56.5^{\circ}$, respectively, vividly showing the existence of nanocrystalline-Si phase. This results are in good agreement with the other XRD patterns of three peaks at $2 \theta \sim 28.4^{\circ}, 47.5^{\circ}$ and $56.1^{\circ}$ [30]. The higher the dilution ratio $R$, the crystal grain size increases (as evidenced from Raman spectra) with higher crystallinity (the volume fraction of partially nanocrystalline structure) with the increase of the hydrogen dilution ratio. Therefore, it is concluded that the hydrogen dilution ratio in PECVD is a critical processing factor for the growth of nc-Si:H films.

\subsection{Raman Spectroscopy Analysis}

Raman spectroscopy is used to investigate the nanocrystalline structure of deposited films. Figure 4 shows the Raman spectra of the nc-Si:H films deposited at different hydrogen dilution ratio $(R)$ ranging from 5 to 40 . The volume fraction of crystallites $\left(X_{\text {Raman }}\right)$ and crystallite size $\left(d_{\text {Raman }}\right)$ of nc-Si:H films can be calculated using the Levenberg-Marquardt method by de-convoluting into three peaks as a crystalline peak $\left(\sim 510 \mathrm{~cm}^{-1}\right)$, an amorphous peak $\left(\sim 475 \mathrm{~cm}^{-1}\right)$ and an intermediate peak $\left(\sim 490 \mathrm{~cm}^{-1}\right)$, respectively [31]. Typical de-convoluted Raman spectra for nc-Si:H film deposited at $R=40$ are shown in Figure 5 . The crystalline fraction $\left(X_{\text {Raman }}\right)$ can be calculated [31]:

$$
X_{\text {Raman }}=\frac{I_{\mathrm{C}}+I_{\mathrm{m}}}{I_{\mathrm{C}}+I_{\mathrm{m}}+I_{\mathrm{a}}}
$$

where $I_{\mathrm{C}}, I_{\mathrm{m}}$ and $I_{\mathrm{a}}$ are the integrated intensity of $520 \mathrm{~cm}^{-1}$ (the crystalline phase), $500 \mathrm{~cm}^{-1}$ (the intermediate phase) and $480 \mathrm{~cm}^{-1}$ (the amorphous phase). The crystallite size $\left(d_{\text {Raman }}\right)$ can also be calculated:

$$
d_{\text {Raman }}=2 \pi \sqrt{\frac{\beta}{\Delta \omega}}
$$

where $\Delta \omega$ is the peak shift compared to c-Si peak located $\sim 520 \mathrm{~cm}^{-1}$ and $\beta=2.0 \mathrm{~cm}^{-1} \mathrm{~nm}^{2}$ [8].

At a low hydrogen dilution ratio $(R=5,10$ and 20$)$ as seen in Figure 4, the deposited films show the typical a-Si:H absorption peak centered $\sim 480 \mathrm{~cm}^{-1}$. However, the onset of nanocrystallization can be experimentally observed of the film deposited at a hydrogen dilution ratio $(R=30)$, which corresponds to the Transverse Optic (TO) phonon peak centred $-507 \mathrm{~cm}^{-1}$ of the nanocrystalline phase [32]. For this film, $X_{\text {Raman }}$ is calculated $\sim 86.13 \%$ and $d_{\text {Raman }}$ is $\sim 2.46 \mathrm{~nm}$. Further increasing in hydrogen dilution ratio $(R=40)$, the peak shifts towards $\sim 509 \mathrm{~cm}^{-1}$ which indicates the increase in the volume fraction of crystallites and its size. For this film, $X_{\text {Raman }}$ is $\sim 89.25 \%$ and $d_{\text {Raman }}$ is $\sim 2.68 \mathrm{~nm}$. The increase in hydrogen dilution ratio $(R)$ in PECVD results in an amorphous-to-nanocrystalline transition in the film. Previously reported similar results for nc-Si:H films deposited by using layer-by-layer (LBL) deposition [33] and increasing RF power [30] concurrently promotes the hydrogen etching and nano-crystallization in the films. Therefore, Raman spectroscopy analysis indicates that the critical process parameter includes both hydrogen dilution ratio and RF power in PECVD, which are functionally equivalent to induce nc-Si:H films. The Raman spectra of the amorphous Si films for the peak at $480 \mathrm{~cm}^{-1}$ for the dilution ratio $(R=5,10$ and 20) were measured and the full width at half maximum (FWHM) was calculated as $46.8 \mathrm{~cm}^{-1}, 48.4 \mathrm{~cm}^{-1}$, and $54.3 \mathrm{~cm}^{-1}$, respectively. The above measurement is in agreement with the reported Raman spectra [34] of the amorphous Si films such that the FWHM is around $53 \pm 7 \mathrm{~cm}^{-1}$. 


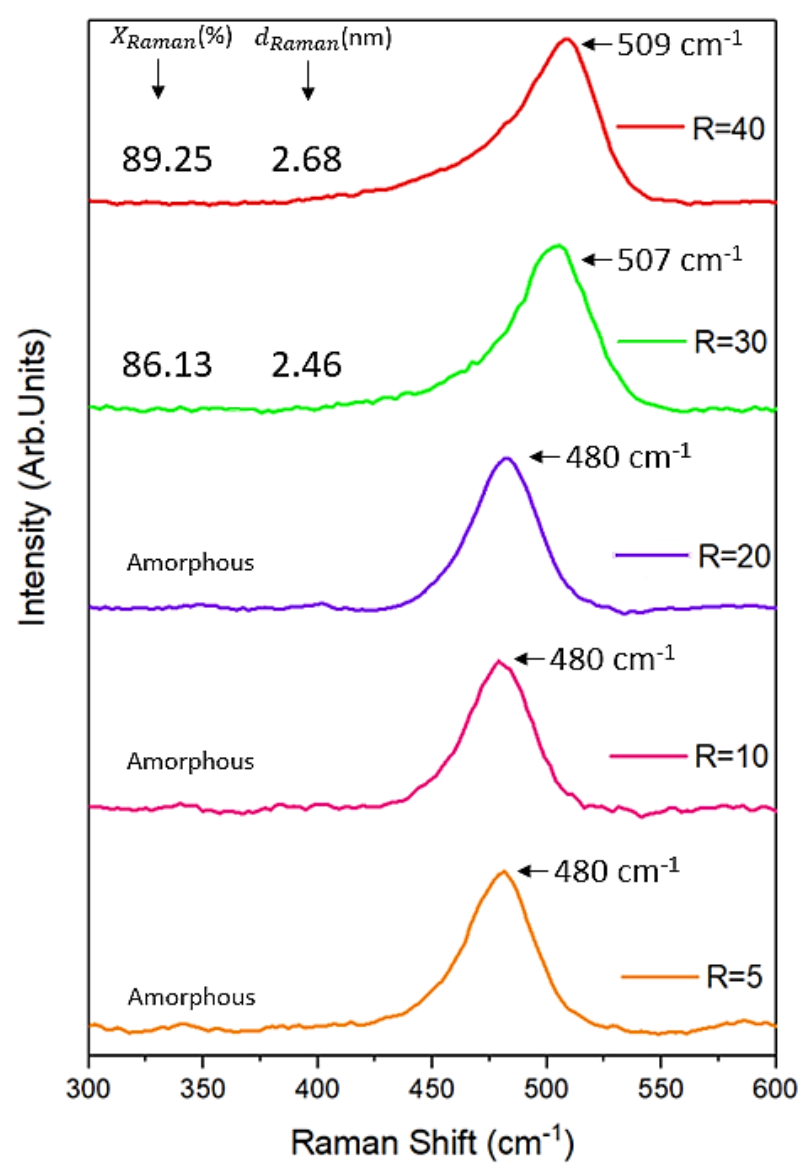

Figure 4. Raman spectra of nc-Si:H films deposited as a function of different hydrogen dilution ratio $(R)$ using the PECVD method.

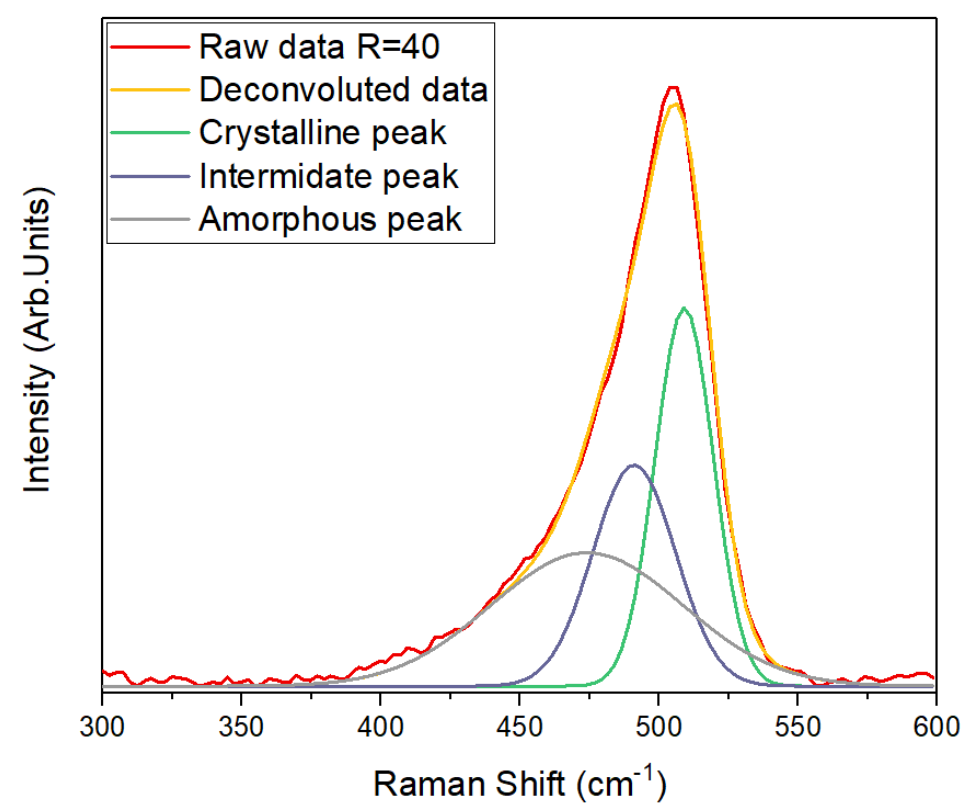

Figure 5. Typical Gaussian de-convoluted Raman spectra of nc-Si:H films deposited at hydrogen dilution ratio $(R=40)$ using PECVD; Raman spectra of the nano-crystalline silicon intrinsic layers (yellow line), and the red line is fitted lines from three Gaussian peaks at $\sim 47, \sim 490$, and $\sim 510 \mathrm{~cm}^{-1}$. 


\subsection{Fourier Transform Infra-Red (FTIR) Spectroscopy Analysis}

In order to investigate the hydrogen bonding and resultant total hydrogen content in the nc-Si:H film, FTIR spectra of different dilution ratios are performed in Figure 6. It can be measured that two major absorption bands centered at $\sim 620$ and $\sim 2000 \mathrm{~cm}^{-1}$ (wagging/stretching modes, respectively), which are closely related to the vibrations of mono-hydrogen $(\mathrm{Si}-\mathrm{H})$ bonded species [35]. The spectra also exhibit an absorption peak centered at $\sim 1060 \mathrm{~cm}^{-1}$, which can be $\mathrm{Si}-\mathrm{O}-\mathrm{Si}$ stretching vibrations of a typical undoped nc-Si:H thin films [36]. In addition, a lesser intensity peak centered at $\sim 885 \mathrm{~cm}^{-1}$ has been observed as the bending vibrational modes of $\mathrm{Si}-\mathrm{H}_{2}$ [37]. With the increase in hydrogen dilution ratio $(R)$, the intensity of absorption band at $\sim 620 \mathrm{~cm}^{-1}$ also incrementally increases. In summary, the increase of hydrogen dilution ratio $(R)$ will promote the increased intensity at $\sim 620 \mathrm{~cm}^{-1}$ while as absorption band centered at $2000 \mathrm{~cm}^{-1}$ shifts incrementally toward the peak at $2100 \mathrm{~cm}^{-1}$. The di-hydride $\left(\mathrm{Si}-\mathrm{H}_{2}\right)$ and poly-hydride $\left(\mathrm{Si}-\mathrm{H}_{2}\right)_{n}$ bonded species can be assigned as $\sim 2100 \mathrm{~cm}^{-1}$ stretching vibrational modes [38]. The experimental results indicate that, with an increase in hydrogen dilution ratio $(R)$, the absorption peak shifts from $\mathrm{Si}-\mathrm{H}$ to $\mathrm{Si}-\mathrm{H}_{2}$ and $\left(\mathrm{Si}-\mathrm{H}_{2}\right)_{n}$ bonded species in films. In addition, it has been reported that the integrated intensity of the peak at $620 \mathrm{~cm}^{-1}$ is the best reliable measure of hydrogen content $\left(C_{H}\right)$ [39] by taking the oscillator strength value [37].

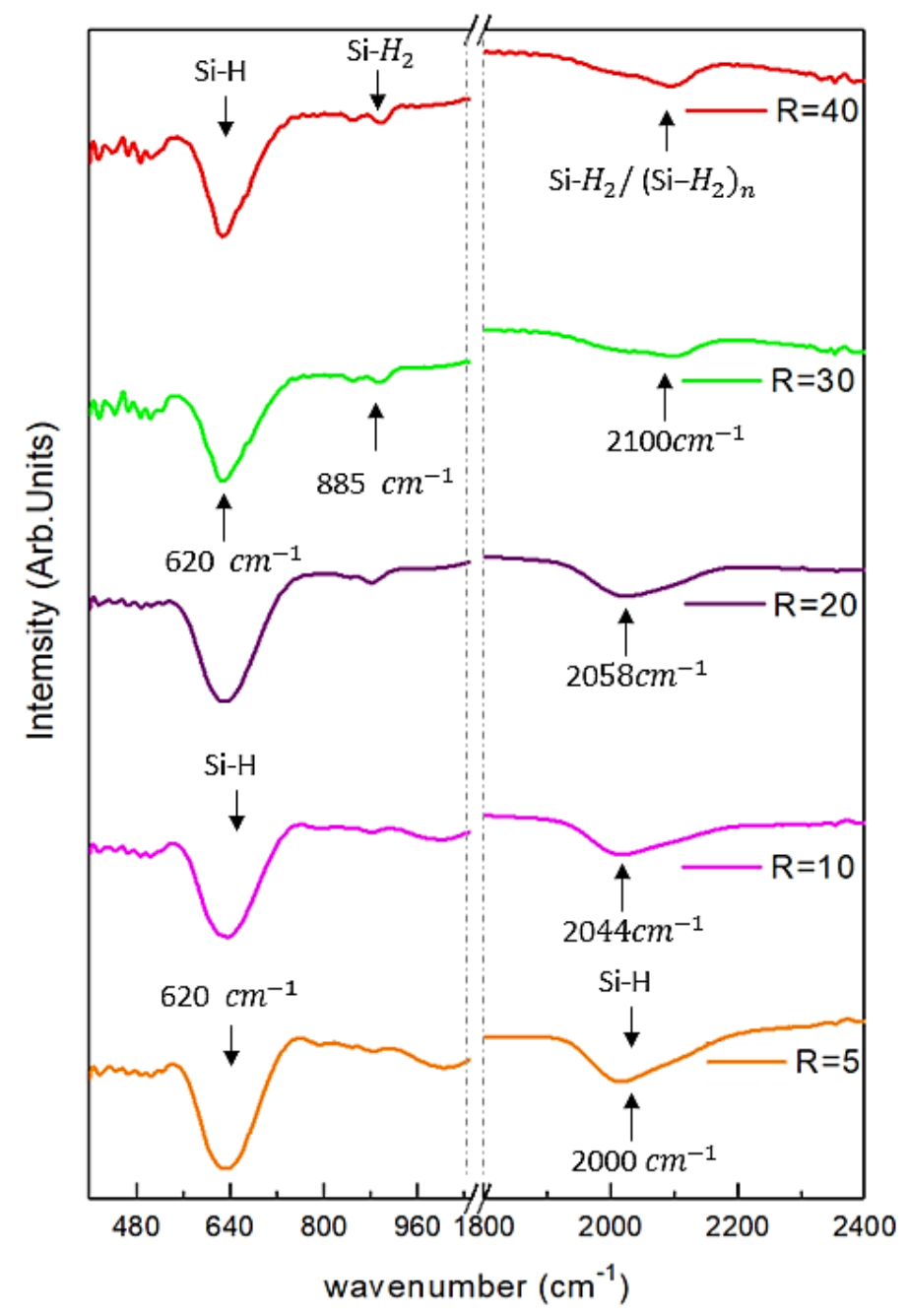

Figure 6. FTIR absorbance spectra of nc-Si:H films (at normalized thickness) deposited by PECVD at different hydrogen dilution ratios $(R)$. The signal located $620 \mathrm{~cm}^{-1}$ and $2100 \mathrm{~cm}^{-1}$ are assigned as the wagging/rocking and stretching mode of nc-Si-H bond, respectively (see the text). 
Figure 7 shows the relationship between the hydrogen content $\left(C_{\mathrm{H}}\right)$ and different hydrogen dilution ratio $(R)$. It is experimentally demonstrated that hydrogen content initially increases with the increase in dilution ratio $(R)$ from 10 to 20, then drops abruptly in the $R$ range of 20-30, and follows the gradually increasing hydrogen content as $R$ values from 30 to 40 . A previously reported hydrogen rich study indicated that an increase in RF power promotes the silane dissociation and produces

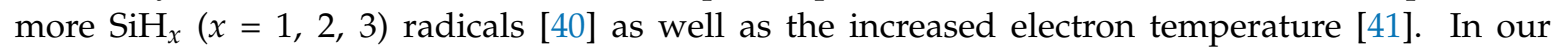
study, RF power is set at $100 \mathrm{~W}$, while the hydrogen dilution ratio $(R)$ shows the similar impact such that the hydrogen rich precursors have higher sticking probability as the hydrogen content increases. A similar trend also indicates that an increase in hydrogen dilution ratio $(R)$ also boosts the density of atomic $\mathrm{H}$ in the deposition chamber and further enhances the surface diffusion with a hydrogen-accumulated growing surface [42]. Both the synergetic effect of the hydrogen etching effect [43] and amorphous-to-nanocrystalline transition can be observed in a hydrogen dilution ratio $(R)$ range of 30-40, which is in agreement with the Raman shift in Figure 4.

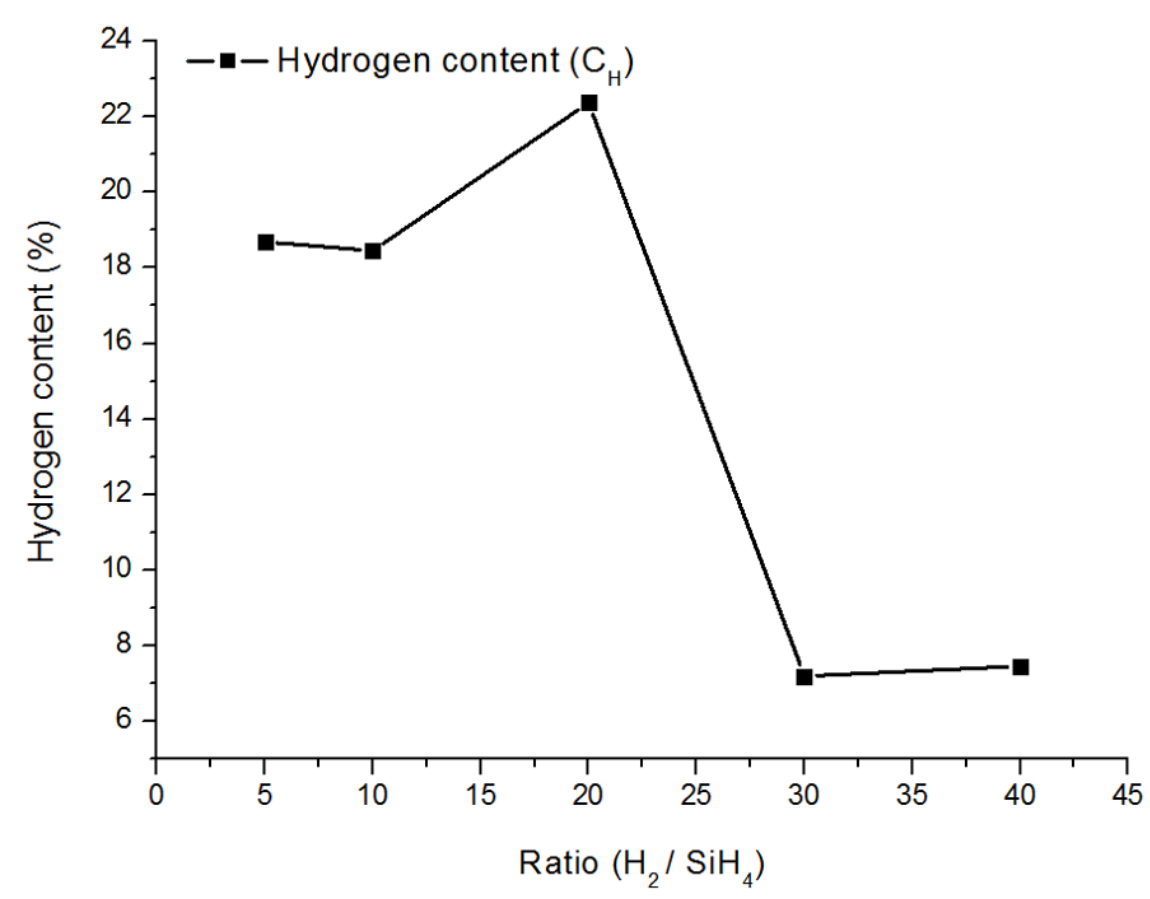

Figure 7. Variation of hydrogen content as a function of hydrogen dilution ratio $(R)$ for nc-Si:H films.

\subsection{Optical Emission Spectra (OES) Spectroscopy Analysis}

Figure 8a shows a series of OES of RF glow discharges of $\mathrm{H}_{\alpha}{ }^{*} / \mathrm{SiH}^{*}$ and $\mathrm{Si}^{*} / \mathrm{SiH}^{*}$ with a different dilution ratio $(R)$. The main characteristic spectra of excited radicals correspond to the emission of $\mathrm{SiH}^{*}(414.30 \mathrm{~nm}), \mathrm{H}_{\alpha}(486.10 \mathrm{~nm}), \mathrm{H}_{\beta}(656.30 \mathrm{~nm}), \mathrm{Ar}^{*}(750.30 \mathrm{~nm})$ and $\mathrm{O}^{*}(844.30 \mathrm{~nm})$, which is directly correlated with the $\mathrm{SiH}_{4}$ electron collision and dissociative excitation. Spatially resolved OES measurements can be used to record the $\mathrm{SiH}$ radicals in axial concentration profiles. Plots of crystallization rate indexes $\left(\mathrm{H}_{\alpha}{ }^{*} / \mathrm{SiH}^{*}\right)$ and electron temperature indexes $\left(\mathrm{Si}^{*} / \mathrm{SiH}^{*}\right)$ versus dilution ratio $(R)$ are shown in Figure $8 \mathrm{~b}$. The result shows that the crystallization rate index $\left(\mathrm{H}_{\alpha}{ }^{*} / \mathrm{SiH}^{*}\right)$ increases when the dilution ratio rises, resulting in the opposite trend of the deposition rate. On the other hand, the electron temperature $\left(\mathrm{Si}^{*} / \mathrm{SiH}^{*}\right)$ is increasing along with a dilution ratio $(R)$ increase, causing increased ion bombardment [29] and thus decreasing the deposition rate. 


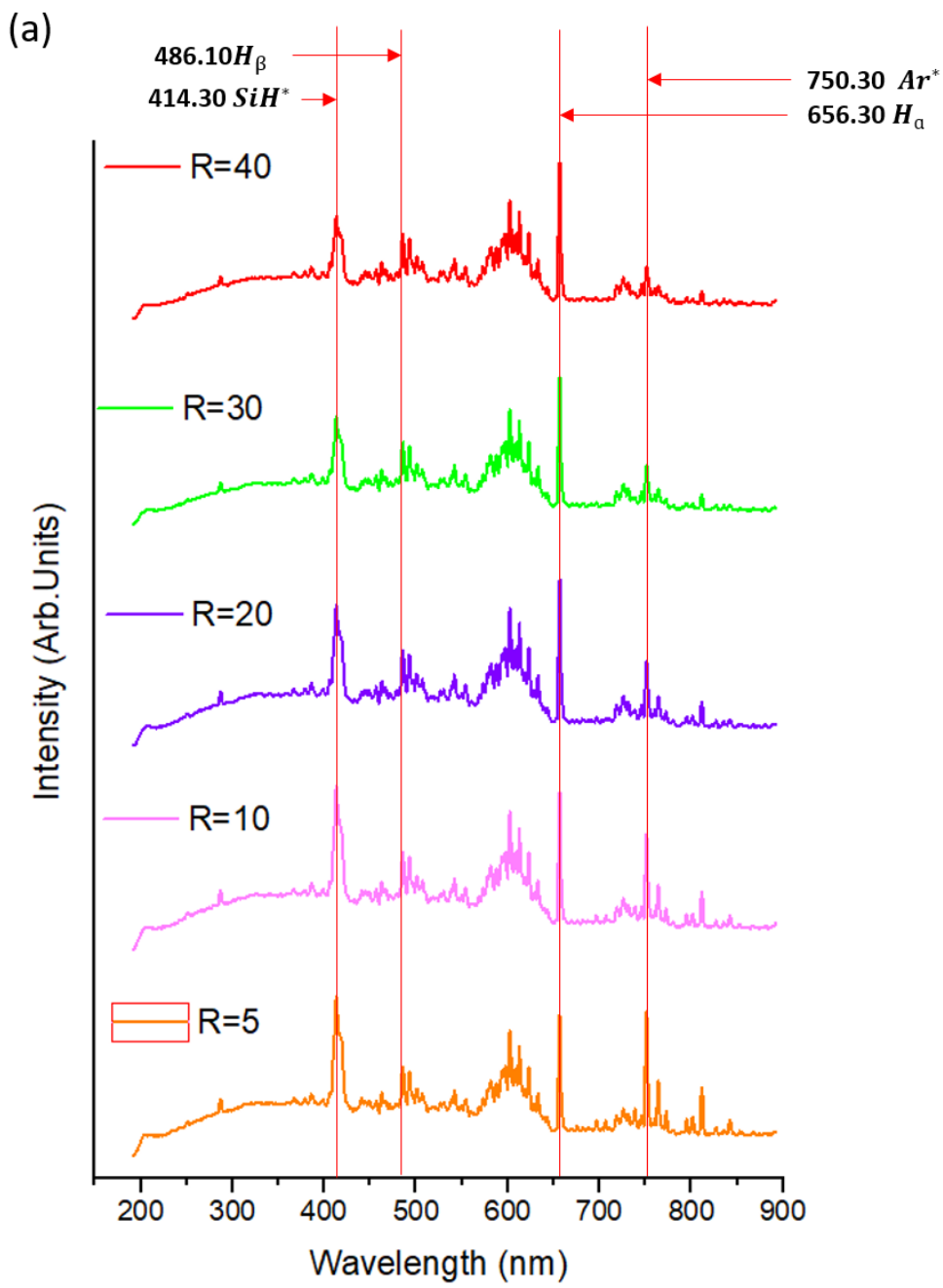

(b)

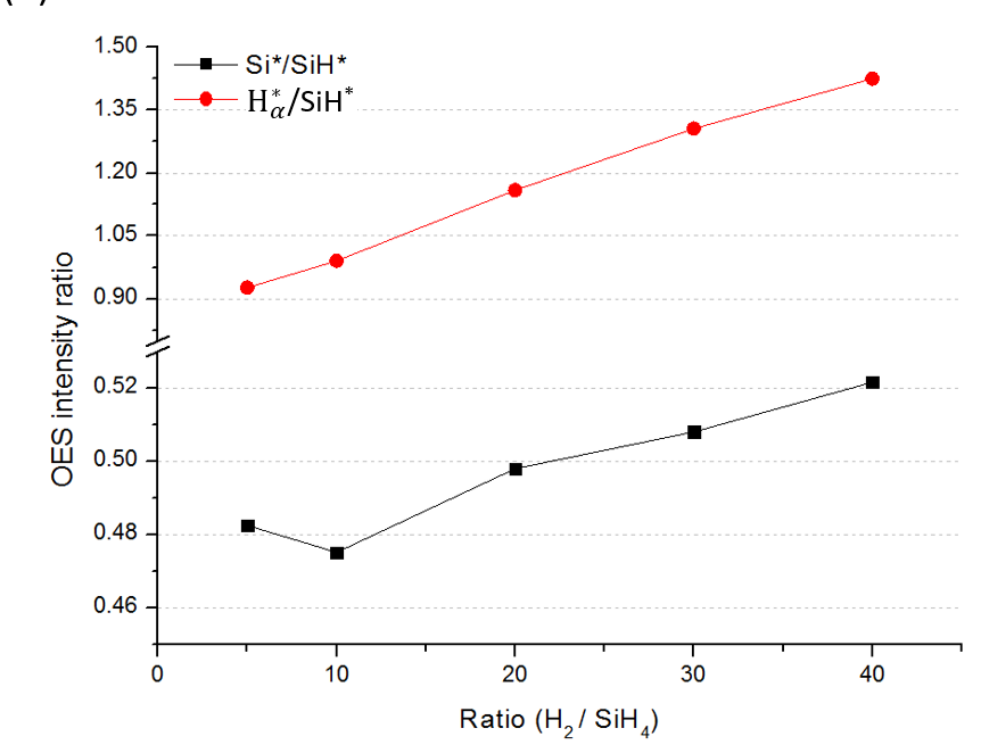

Figure 8. (a) Optical emission spectra measured during the deposition of nc-Si:H thin film as a function of hydrogen dilution ratio $(R)$. Some prominent optical emission peaks and band structures for silane-hydrogen plasma are labelled; (b) OES intensity ratio of $\mathrm{H}_{\alpha}{ }^{*} / \mathrm{SiH}^{*}$ (red line) and ratio of electron temperature $\mathrm{Si}^{*} / \mathrm{SiH}^{*}$ (black line) calculated during the deposition of nc-Si:H thin film as a function of varying hydrogen dilution ratio $(R)$. 


\subsection{Quadruple Mass Spectra (QMS) Spectroscopy Analysis}

Measured results of QMS during nc-Si:H deposition in Figure 9 indicates some distinguishably identified fingerprints of the radicals $\mathrm{SiH}_{x}{ }^{+}(0<x<4)$. The TIMS method shows the trends in relative densities of four mono-silane radicals $\left(\mathrm{SiH}_{3}{ }^{+}, \mathrm{SiH}_{2}{ }^{+}, \mathrm{SiH}^{+}\right.$and $\left.\mathrm{Si}^{+}\right)$by varying the hydrogen dilution ratio in argon-silane-hydrogen plasmas. PECVD nc-Si:H deposition shows that a critical point of relative densities is obtained as the $\mathrm{SiH}^{+}$radical reached a threshold value at $R \sim 30\left(\mathrm{SiH}_{3}{ }^{+}\right.$radicals remain almost unchanged, pink bar). This study shows significantly different plasma composition at different silane dilution in hydrogen $(R=5-40)$, validating that $\mathrm{SiH}^{+}$is the dominant radical in the growth of nc-Si:H layers, [44]. Therefore, in the range of $R=30$ and 40 of high silane dilution, QMS experiments confirmed that nano-crystalline silicon (nc-Si:H) growth is closely related to the depletion of higher silane radicals $[42,45]$.

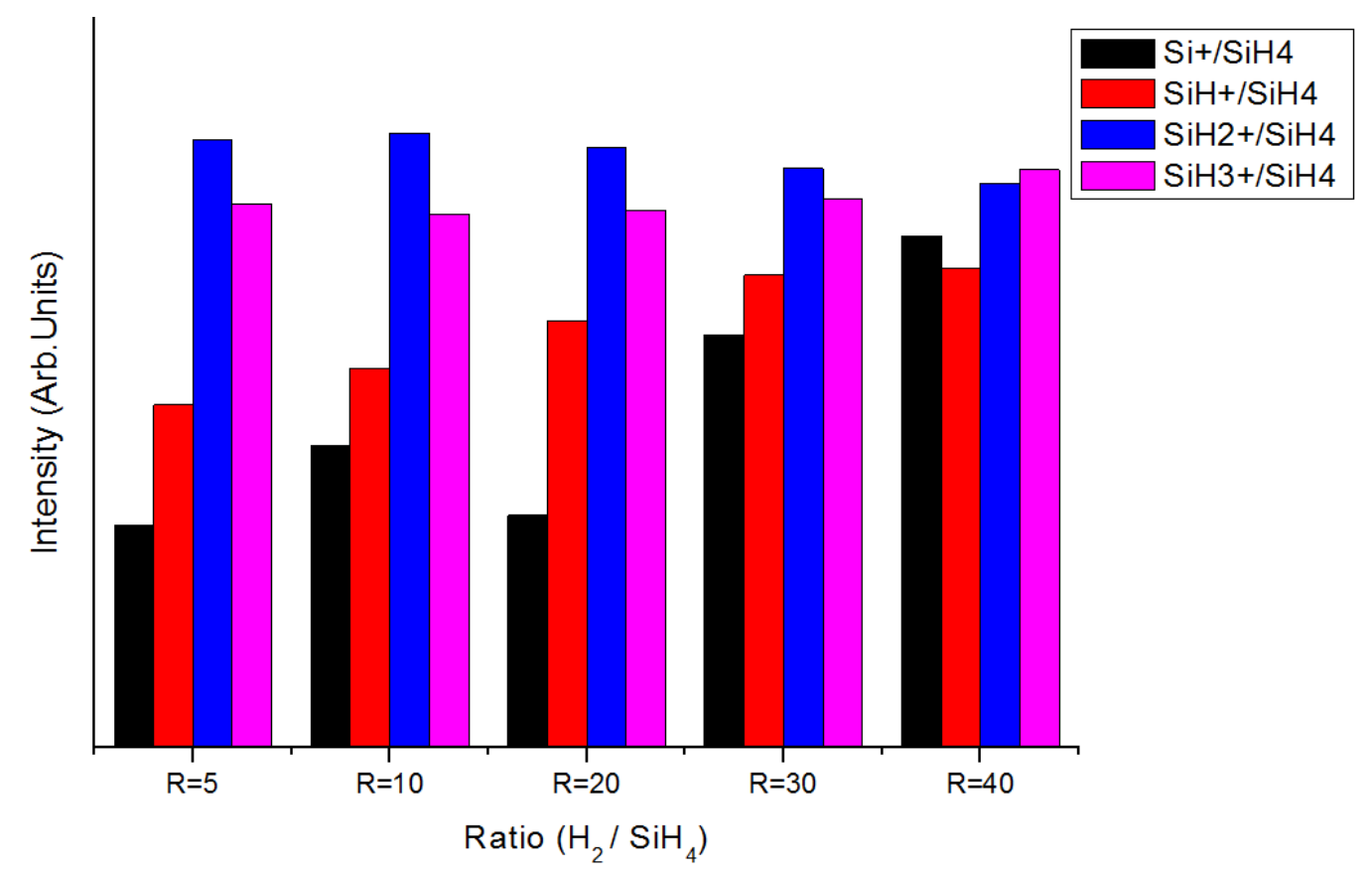

Figure 9. Relative density QMS measured during typical nc-Si:H deposition as a function of varying hydrogen dilution ratios $(R)$.

\section{Conclusions}

Hydrogenated nanocrystalline silicon (nc-Si:H) thin films were grown by the PECVD system. The results show that as hydrogen dilution ratio $(R)$ increases, the deposition rate decreases. It was also revealed by low angle XRD and Raman spectroscopy that nc-Si:H films can be induced via the adjustment of hydrogen dilution ratio $(R)$. Moreover, FTIR spectroscopy indicates that the shifts of predominant hydrogen bonding (from $\mathrm{Si}-\mathrm{H}$ to $\mathrm{Si}-\mathrm{H}_{2}$ and $\left(\mathrm{Si}-\mathrm{H}_{2}\right)_{n}$ bonded species) are closely related to the increase in the hydrogen dilution ratio $(R)$. At the dilution ratio $(R=40)$, nc-Si:H films have a crystallite size of $\sim 2.3 \mathrm{~nm}$ with a degree of crystallinity and $\sim 89.2 \%$ were obtained with a low hydrogen content $\left(C_{\mathrm{H}}=7.45 \%\right)$ at moderately low deposition rate $(0.69 \AA / \mathrm{s})$. Furthermore, the QMS plasma diagnostic tool also confirmed the existence of a direct correlation between nc-Si:H film growth and the $\mathrm{SiH}^{+}$radicals film, via the tuning of a hydrogen dilution ratio in the range of $5-40$. Overall, this study shows a good and important correlation of plasma characteristics by in situ OES/QMS and the end resulted in film characteristics by XRD, Raman and FTIR, for the transition of a-Si:H to nc-Si:H film by a hydrogen dilution ratio. 
Author Contributions: Conceptualization, T.T.L., Y.-K.F. and C.-C.L.; Methodology, Y.-L.H.; Software, L.-H.K. and H.-J.H.; Validation, Y.-L.H., L.-H.K. and H.-J.H.; Formal Analysis, Y.-L.H., L.-H.K. and H.-J.H.; Investigation, T.T.L. and Y.-K.F.; Curation, T.T.L, Y.-K.F., C.-C.L. and Y.-L.H.; Writing-Original Draft Preparation, Y.-K.F., T.T.L., L.-H.K. and H.-J.H.; Writing-Review \& Editing, Y.-K.F., T.T.L., L.-H.K. and H.-J.H.; Visualization, L.-H.K. and H.-J.H.; Supervision, T.T.L., Y.-K.F. and C.-C.L.; Project Administration, T.T.L., Y.-K.F. and C.-C.L.

Funding: This research was financially funded by the Delta Electronics, Inc., Taiwan under the grant number 10613082.

Acknowledgments: This study was financially supported by Delta Electronics, Inc., Taiwan and Department of Mechanical Engineering, Optical Science Center and Department of Optics and Photonics, National Central University, Taiwan.

Conflicts of Interest: The authors declare no conflict of interest.

\section{References}

1. Zhou, H.P.; Wei, D.Y.; Xu, S.; Xiao, S.Q.; Xu, L.X.; Huang, S.Y.; Guo, Y.N.; Yan, W.S.; Xu, M. Crystalline silicon surface passivation by intrinsic silicon thin films deposited by low-frequency inductively coupled plasma. J. Appl. Phys. 2012, 112, 013708. [CrossRef]

2. Tong, G.B.; Aspanut, Z.; Muhamad, M.R.; Rahman, S.A. Optical properties and crystallinity of hydrogenated nanocrystalline silicon (nc-Si: H) thin films deposited by RF-PECVD. Vacuum 2012, 86, 1195-1202. [CrossRef]

3. Dutta, P.; Paul, S.; Galipeau, D.; Bommisetty, V. Effect of hydrogen plasma treatment on the surface morphology, microstructure and electronic transport properties of nc-Si:H. Thin Solid Films 2010, 518, 6811-6817. [CrossRef]

4. Zhang, L.; Shen, H.L.; Jiang, X.F.; Qian, B.; Han, Z.D.; Hou, H.H. Influence of annealing temperature on the properties of polycrystalline silicon films formed by rapid thermal annealing of a-Si:H films. J. Mater. Sci. Mater. Electron. 2013, 24, 4209-4212. [CrossRef]

5. Adikaari, A.A.D.T.; Mudugamuwa, N.K.; Silva, S.R.P. Nanocrystalline silicon solar cells from excimer laser crystallization of amorphous silicon. Sol. Energy Mater. Sol. Cells 2008, 92, 634-638. [CrossRef]

6. Shim, J.H.; Im, S.; Kim, Y.J.; Cho, N.H. Nanostructural and optical features of hydrogenated nanocrystalline silicon films prepared by aluminium-induced crystallization. Thin Solid Films 2006, 503, 55-59. [CrossRef]

7. Kaneko, T.; Wakagi, M.; Onisawa, K.; Minemura, T. Change in crystalline morphologies of polycrystalline silicon films prepared by radio-frequency plasma-enhanced chemical vapor deposition using $\mathrm{SiF}_{4}+\mathrm{H}_{2}$ gas mixture at $350{ }^{\circ} \mathrm{C}$. Appl. Phys. Lett. 1994, 64, 1865. [CrossRef]

8. He, Y.; Yin, C.; Cheng, G.; Wang, L.; Liu, X.; Hu, G.Y. The structure and properties of nanosize crystalline silicon films. J. Appl. Phys. 1994, 75, 797. [CrossRef]

9. Banerjee, A.; Liu, F.S.; Beglau, D.; Tining, S.; Pietka, G.; Yang, J.; Guha, S. 12.0\% Efficiency on Large-Area, Encapsulated, Multijunction nc-Si:H-Based Solar Cells. IEEE J. Photovolt. 2012, 2, 104-108. [CrossRef]

10. Bakr, N.A.; Funde, A.M.; Waman, V.S.; Kamble, M.M.; Hawaldar, R.R.; Amalnerkar, D.P.; Sathe, V.G.; Gosavi, S.W.; Jadkar, S.R. Influence of deposition pressure on structural, optical and electrical properties of nc-Si:H films deposited by HW-CVD. J. Phys. Chem. Solids 2011, 72, 685-691. [CrossRef]

11. Goh, B.T.; Wah, C.K.; Aspanut, Z.; Rahman, S.A. Structural and optical properties of $n c-S i: H$ thin films deposited by layer-by-layer technique. J. Mater. Sci. Mater. Electron. 2014, 25, 286-296. [CrossRef]

12. He, H.; Ye, C.; Wang, X.; Huang, F.; Liu, Y. Effect of driving frequency on growth and structure of silicon films deposited by radio-frequency and very-High-frequency magnetron sputtering. ECS J. Solid State Sci. Technol. 2014, 3, Q74-Q78. [CrossRef]

13. Lee, S.E.; Park, Y.C. Highly-conductive B-doped $n c-S i: H$ thin films deposited at room temperature by using SLAN ECR-PECVD. J. Korean Phys. Soc. 2014, 65, 651-656. [CrossRef]

14. Peng, S.; Wang, D.; Yang, F.; Wang, Z.; Ma, F. Grown Low-Temperature Microcrystalline Silicon Thin Film by VHF PECVD for Thin Films Solar Cell. J. Nanomater. 2015, 2015, 327596. [CrossRef]

15. Brodsky, M.; Cardona, M.; Cuomo, J.J. Infrared and Raman spectra of the silicon-hydrogen bonds in amorphous silicon prepared by glow discharge and sputtering. Phys. Rev. B 1977, 16, 3556. [CrossRef]

16. Tauc, J. Absorption edge and internal electric fields in amorphous semiconductors. Mater. Res. Bull. 1970, 5, 721-729. [CrossRef] 
17. Hsieh, Y.L.; Lee, C.C.; Lu, C.C.; Fuh, Y.K.; Chang, J.Y.; Lee, J.Y.; Li, T.T. Structural and electrical investigations of a-Si:H(i) and a-Si:H(n $\left.{ }^{+}\right)$stacked layers for improving the interface and passivation qualities. J. Photonics Energy 2017, 7, 035503. [CrossRef]

18. Dushaq, G.; Nayfeh, A.; Rasras, M. Tuning the optical properties of RF-PECVD grown $\mu c-S i: H$ thin films using different hydrogen flow rate. Superlattice Microstruct. 2017, 107, 172-177. [CrossRef]

19. Mataras, D.; Cavadias, S.; Rapakoulias, D. Spatial profiles of reactive intermediates in RF silane discharges. J. Appl. Phys. 1989, 66, 119. [CrossRef]

20. Dingemans, G.; van den Donker, M.N.; Gordijn, A.; Kessels, W.M.M.; van de Sanden, M.C.M. Probing the phase composition of silicon films in situ by etch product detection. Appl. Phys. Lett. 2007, 91, 161902. [CrossRef]

21. Fantz, U. Spectroscopic diagnostics and modelling of silane microwave plasmas. Plasma Phys. Control. Fusion 1998, 40, 1035. [CrossRef]

22. Lisovskiy, V.; Booth, J.-P.; Landry, K.; Douai, D.; Cassagne, V.; Yegorenkov, V. RF discharge dissociative mode in $\mathrm{NF}_{3}$ and $\mathrm{SiH}_{4}$. Appl. Phys. D 2007, 40, 6631. [CrossRef]

23. Nunomura, S.; Yoshida, I.; Kondo, M. Time-dependent gas phase kinetics in a hydrogen diluted silane plasma. Appl. Phys. Lett. 2009, 94, 071502. [CrossRef]

24. Strahm, B.; Howling, A.A.; Sansonnens, L.; Hollenstein, C. Plasma silane concentration as a determining factor for the transition from amorphous to microcrystalline silicon in $\mathrm{SiH}_{4} / \mathrm{H}_{2}$ discharges. Plasma Sources Sci. Technol. 2007, 16, 80. [CrossRef]

25. Howling, A.; Strahm, B.; Hollenstein, C. Non-intrusive plasma diagnostics for the deposition of large area thin film silicon. Thin Solid Films 2009, 517, 6218-6224. [CrossRef]

26. Rath, J.K. Low temperature polycrystalline silicon: A review on deposition, physical properties and solar cell applications. Sol. Energy Mater. Sol. Cells 2003, 76, 431-487. [CrossRef]

27. Jellison, J.G.E.; Modine, F.A. Parameterization of the optical functions of amorphous materials in the interband region. Appl. Phys. Lett. 1996, 69, 371. [CrossRef]

28. Lin, L.J.H.; Chiou, Y.-P. Improving thin-film crystalline silicon solar cell efficiency with back surface field layer and blaze diffractive grating. Sol. Energy 2012, 86, 1485-1490. [CrossRef]

29. Matsuda, A. Growth mechanism of microcrystalline silicon obtained from reactive plasmas. Thin Solid Films 1999, 337, 1-6. [CrossRef]

30. Jadhavar, A.; Pawbake, A.; Waykar, R.; Waman, V.I.; Rondiya, S.; Shinde, O.; Kulkarni, R.; Rokade, A.; Bhorde, A.; Funde, A.; et al. Influence of RF power on structural optical and electrical properties of hydrogenated nano-crystalline silicon (nc-Si:H) thin films deposited by PE-CVD. J. Mater. Sci. Mater. Electron. 2016, 27, 12365-12373. [CrossRef]

31. Marquardt, D. An Algorithm for Least-Squares Estimation of Nonlinear Parameters. J. Soc. Ind. Appl. Math. 1963, 11, 431-441. [CrossRef]

32. Li, Z.; Li, W.; Jiang, Y.; Cai, H.; Gong, Y.; He, J. Raman characterization of the structural evolution in amorphous and partially nanocrystalline hydrogenated silicon thin films prepared by PECVD. J. Raman Spectrosc. 2011, 42, 415-421. [CrossRef]

33. Tong, G.B.; Muhamad, M.R.; Rahman, S.A. Effects of RF Power on structural properties of nc-Si:H thin films deposited by layer-by-layer (LbL) deposition Technique. Sains Malays. 2012, 41, 993-1000.

34. Droz, C.; Vallat-Sauvain, E.; Bailat, J.; Feitknecht, L.; Meier, J.; Shah, A. Relationship between Raman crystallinity and open-circuit voltage in microcrystalline silicon solar cells. Sol. Energy Mater. Sol. Cells 2004, 81, 61-71. [CrossRef]

35. Lucovsky, G. Vibrational spectroscopy of hydrogenated amorphous silicon alloys. Sol. Cells 1980, 2, 431-442. [CrossRef]

36. Halindintwali, S.; Knoesen, D.; Swanepoel, R.; Julies, B.; Arendse, C.; Muller, T.; Theron, C.; Gordijn, A.; Bronsveld, P.; Rath, J.K.; et al. Improved stability of intrinsic nanocrystalline Si thin films deposited by hot-wire chemical vapour deposition technique. Thin Solid Films 2007, 515, 8040-8044. [CrossRef]

37. Knights, J.C.; Lucovsky, G.; Nemanich, R.J. Defects in plasma-deposited a-Si:H. J. Non-Cryst. Solids 1979, 32, 393-403. [CrossRef]

38. Tsu, D.; Lucovsky, G.; Dadison, B. Effects of the nearest neighbors and the alloy matrix on SiH stretching vibrations in the amorphous $\mathrm{SiO}_{\mathrm{r}}: \mathrm{H}(0<\mathrm{r}<2)$ alloy system. Phys. Rev. B 1989, 40, 1795-1805. 
39. Jones, A.; Ahmed, W.; Hassan, I.; Rego, C.; Sein, H.; Amar, M.; Jackson, M. The impact of inert gases on the structure, properties and growth of nanocrystalline diamond. J. Phys. 2003, 15, S2969. [CrossRef]

40. Chen, C.Z.; Qiu, S.H.; Liu, C.Q.; Dan, W.Y.; Li, P.; Ying, Y.C.; Lin, X. Low temperature fast growth of nanocrystalline silicon films by RF-PECVD from $\mathrm{SiH}_{4} / \mathrm{H}_{2}$ gases: Microstructural characterization. J. Phys. D Appl. Phys. 2008, 41, 195413. [CrossRef]

41. Lin, K.X.; Lin, X.Y.; Yu, Y.P.; Wang, H.; Chen, J.Y. Measurements in silane radio frequency glow discharges using a tuned and heated Langmuir probe. J. Appl. Phys. 1993, 74, 4899. [CrossRef]

42. Kondo, M.; Fukawa, M.; Guo, L.; Matsuda, A. High rate growth of microcrystalline silicon at low temperatures. J. Non-Cryst. Solids 2000, 266-269, 84-89. [CrossRef]

43. Das, C.; Ray, S. Power density in RF-PECVD: A factor for deposition of amorphous silicon thin films and successive solid phase crystallization. J. Phys. D Appl. Phys. 2002, 35, 2211. [CrossRef]

44. Kirner, S.; Gabriel, O.; Stannowski, B.; Rech, B.; Schlatmann, R. The growth of microcrystalline silicon oxide thin films studied by in situ plasma diagnostics. Appl. Phys. Lett. 2013, 102, 051906. [CrossRef]

45. Strahm, B.; Howling, A.A.; Sansonnens, L.; Hollenstein, C. Optimization of the microcrystalline silicon deposition efficiency. J. Vac. Sci. Technol. A 2007, 25, 1198. [CrossRef]

(C) 2018 by the authors. Licensee MDPI, Basel, Switzerland. This article is an open access article distributed under the terms and conditions of the Creative Commons Attribution (CC BY) license (http:/ / creativecommons.org/licenses/by/4.0/). 